\title{
APAKAH FLYPAPER EFFECT TERJADI DI ACEH? STUDI MENGUKUR KEMANDIRIAN KEUANGAN DAERAH
}

\author{
Muhammad Hasan Basri \\ Pusat Informasi dan Kajian Ekonomi (Pike) Aceh
}

Jln. T. Iskandar No. 174A, Lamglumpang-Ulee Kareng, Banda Aceh

Email:mhasanbasri123@gmail.com

Riswandi

Jurusan Ekonomi Pembangunan

Fakultas Ekonomi Universitas Syiah Kuala

Email: rhendratno@yahoo.com; riswandi@fe.unsyiah.ac.id

\begin{abstract}
The objective of this study is to analyse the phenomenon of flypaper effect in Aceh after the implementation of fiscal decentralization. Data used in the study were panel data covering all 23 district/municipalities in Aceh from 2011 to 2013. Pooled Least Square was utilized. The results of this study revealed that ownsource revenue, sharing revenue, special allocation funds, general allocation funds, and special autonomy funds are statistically significant variables and have a positive relation to regional spending. It was proven that flypaper effect has occured in Aceh as the coefficient of the own-source revenue variabel was smaller than that of sharing revenue variabel. This implied that Aceh has been dependent on the national government in term of regional financing. Based on descriptive analysis, provinces having dominant share of tertiary sector to their regional gross domestic products show fiscally independent. In order to achieve fiscal independence, the phenomenon of flypaper effect could be overcomed by shifting the economic structure from the primary and secondary to the tertiary sectors of the economy. In doing so, the contribution of own-source revenue to regional spending outweigh intergovernment transfer funds from national government.
\end{abstract}

Keywords: flypaper effect, pooled least square, panel data 


\section{PENDAHULUAN}

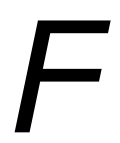

lypaper Effect istilah yang pertama sekali diperkenalkan oleh Arthur Okun merupakan salah satu terminologi keuangan daerah yang mendeskripsikan bagaimana respon belanja daerah terhadap dana transfer dari pemerintah ke pemerintah daerah (inter-governmental transfer)dan kemampuan daerah menghasilkan pendapatan aslinya. Istilah ini mulai terkenal setelah serangkain penelitian dilakukan untuk mengukur apakah dengan adanya transfer dana antarpemerintah tersebut membuat pemerintah daerah baik provinsi maupun kabupaten semakin mandiri dari perspektif keuangan publik.

Di era 1960-an, Okun telah menjelaskan bahwa flypaper effect merupakan suatu kondisi saat belanja daerah sangat dirangsang oleh dana transfer dari pemerintah ketimbang dana yang dihimpun dari pemungutan pajak. Fenomena flypaper effect merupakan suatu keadaan yang dapat terjadi ketika pemerintah daerah merespon belanja daerah lebih banyak menggunakan dana perimbangan untuk belanja daerah ketimbang menggunakan Pendapatan Asli Daerah (PAD). Dalam arti yang lebih luas, fenomena ini menunjukkan bahwa transfer akan meningkatkan belanja pemerintah daerah yang lebih besar daripada penerimaan transfer itu sendiri (Turnbull, 1992). Menurut Maimunah (2006), flypaper effect adalah suatu kondisi yang terjadi saat pemerintah merespon belanja lebih banyak dengan menggunakan dana transfer (grants) yang diproksikan dengan DAU daripada menggunakan kemampuan sendiri, diproksikan dengan PAD.

Setelah Okun mendefinisikan flypaper effect, Henderson (1968) dan Gramlich (1969) mulai melakukan penelitian yang berfokus pada hubungan pajak dan belanja pemerintah daerah.Sejumlah penelitian kemudian berkembang untuk membuktikan apakah flypaper effect terjadi atau tidak di daerah, termasuk di Indonesia.Penelitian tersebut menguji secara secara umum menjelaskan flypaper effect sebagai keadaan dimana pemerintah daerah merespon belanja daerah lebih banyak menggunakan dana perimbangan atau transfer dari pemerintah daripada menggunakan PAD.

Beberapa hasil penelitian membuktikan bahwa flypaper effect terbukti terjadi di Sumatera Utara (Listrioni, 2012), di Jawa Tengah (Burhanuddin, 
2012), di Kalimantan (Purnomo, 2011), di Sumatera Selatan (Saputra, et al., 2012) dan di Jawa dan Bali (Abdullah dan Halim, 2004). Secara umum salah satu alasannya adalah karena rendahnya kontribusi PAD dibandingkan dengan dana transfer Pemerintah terhadap belanja daerah.

Sejak otonomi daerah dijalankan mulai tahun 1999, Pemerintah memberikan sejumlah kewenangan kepada pemerintah daerah. Karena pelimpahan kewenangan tersebut, Pemerintah menstrafer sejumlah dana untuk membiayai pelaksanaan tugas-tugas tersebut kepada daerah, atau hal ini sering diistilahkan dengan money follows functions. Transfer dana ini diberikan dalam tiga kelompok besar. Pertama, transfer dana perimbangan dalam bentuk Dana Bagi Hasil (DBH) antara lain DBH Pajak, DBH Cukai Hasil Tembakau, DBH Sumber Daya Alam, Dana Alokasi Umum (DAU), dan Dana Alokasi Khusus (DAK). Kedua, transfer Dana Otonomi Khusus yang diberikan hanya untuk Pemerintah Aceh, Provinsi Papua dan Provinsi Papua Barat. Terakhir, transfer Dana Penyesuaian yang diberikan dalam bentuk Tunjangan Profesi Guru PNS Daerah, Tambahan Penghasilan Guru PNS Daerah, Bantuan Operasional Sekolah, Dana Insentif Daerah dan dana Proyek Pemerintah Daerah dan Desentralisasi (P2D2).

Anggaran Pemerintah yang ditransfer untuk belanja daerah meningkat secara sangat signifikan dari Rp129,81 triliun pada tahun 2004 menjadi Rp528,63 triliun pada tahun 2013. Dari anggaran yang ditransfer tersebut, dana perimbangan memiliki porsi yang tertinggi yaitu mencapai $95 \%$ atau sekitar 122,95 triliun pada tahun 2004, meskipun kemudian porsinya menurun di tahun 2013 menjadi 84\% atau sebesar $\operatorname{Rp} 444,79$ triliun.Sementara itu, porsi dari total transfer dana tersebut untuk pelaksaaan otonomi khusus di Aceh, Papua dan Papua Barat dan dana penyeimbangan meningkat cukup signifikan dari $5 \%$ atau 6,86 triliun pada tahun 2004 menjadi 16\% atau sekitar 83,83 triliun pada tahun 2013.

Bagi Aceh, peningkatan transfer danaPemerintah dalam bentuk dana perimbangan dan dana otonomi khusus menjadikan sumber pendapatan yang sangat besar. Dari satu sisi, hal ini dapat dimaknai bahwa tingkat ketergantungan Aceh terhadap Pemerintah sangat tinggi.Pada tahun 2013, kontribusi PAD Aceh relatif kecil hanya sekitar 11\%. Sementara itu, lainlain pendapatan yang sah dalam bentuk Dana Otonomi Khusus dan Penyesuaian menjadi sumber terbesar mencapai 64 persen dari total 
pendapatan dankemudian disusul pendapatan transfer dalam bentuk dana bagi hasil sumber daya alam, DAK dan DAU sebesar 25 persen.

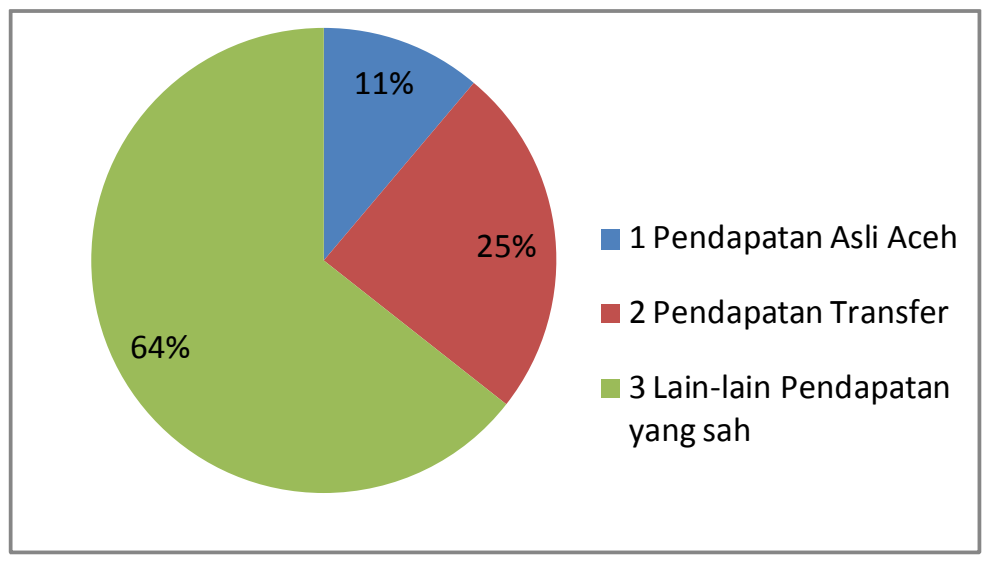

Sumber : Dinas Keuangan Aceh, 2014.

Gambar 1. Komposisi Pendapatan Provinsi Aceh, 2013

Studi ini bertujuan menemukan bukti-bukti empiris apakah flypaper effect terjadi di Aceh, khususnya setelah provinsi ini menerima transfer Dana Otonomi Khusus yang jumlahnya relatif besar.Penelitian ini menarik dilakukan di Aceh karena tiga alasan penting. Pertama apakah dana otonomi khusus dapat mengurangi ketergantungan Aceh dalam jangka panjang atau sebaliknya. Kedua, struktur ekonomi Aceh yang secara umum sama dengan struktur ekonomi provinsi lain di Indonesia yang sangat bergantung pada ekonomi tradisional apakah dapat digeser menjadi struktur ekonomi modern yang berbasis sektor tersier, sektor jasa dan industri manufaktur dan kreatif akibat sumber transfer yang besar terutama tambahan dana dari Dana Otonomi Khusus dan minyak dan gas bumi. Ketiga, studi ini memasukkan komponen dana transfer yang lebih lengkap seperti DOP yang hanya dimiliki oleh Aceh dan Papua dan Papua Barat.

\section{METODE PENELITIAN}

Penelitian ini dilakukan di Aceh dengan menggunakan data sekunder dalam bentuk data panel.Teknik purposive sampling digunakan dalam penelitian ini dengan dua kriteria. Pertama,kabupaten/kota di Provinsi Aceh yang mempublikasikan secara konsisten laporan keuangan daerah

QE Journal | Vol.03 - No.04 December 2014 - 202 
dari tahun 2011-2013 yang tersedia di Badan Pusat Statistik Aceh atau Dinas Keuangan Aceh. Kedua, kabupaten/kota yang tidak dimekarkan pada kurun waktu 2011-2013. Dari kriteria tersebut, maka sampel merupakan populasi dengan cross section sebanyak 23 kabupaten/kota dan time series sebanyak tiga tahun (2011-2013), dengan jumlah sampel 69.

Model analisis yang digunakan dalam penelitian ini adalah dengan menggunakan pengujian data panel dan analisis deskriptif. Dengan data panel, ada tiga metode yang dapat digunakan yaitu Pooled Least Square (PLS) atau Common Effect Model (CEM), Fixed Effect Model (FEM), dan Random Effect Model (REM).Dalam menentukan metode yang terbaik yang digunakan dari ketiga metode tersebut PLS atau CEM, FEM, dan REM, perlu dilakukan pengujian-pengujian berkaitan dengan hal tersebut. Pengujian itu diantaranya adalah uji F, uji Hausman, dan uji LM (Lagrange Multiplier).

Model panel Ordinary Least (OLS) dalam penelitian ini sebagai berikut:

$\mathrm{BD}_{\mathrm{it}}=\beta_{0 \mathrm{it}}+\beta_{1} \mathrm{PAD}_{\mathrm{it}}+\beta_{2} \mathrm{DBH}_{\mathrm{it}}+\beta_{3} \mathrm{DAK}_{\mathrm{it}}+\beta_{4} \mathrm{DAU}_{\mathrm{it}}+\beta_{5} \mathrm{DOP}_{\mathrm{it}}+\mathrm{u}_{\mathrm{it}}$

dimana BD adalah belanja daerah, PAD adalah pendapatan asli daerah, DBH adalah dana bagi hasil, DAK adalah dana alokasi khusus, DAU adalah dana alokasi umum, DOP adalah dana otonomi khusus dan penyesuaian, i adalah kabupaten/kota di Aceh, $t$ adalah waktu (2011 sampai 2013), $\beta_{0}$ adalah konstanta, $\beta_{1-} \beta_{6}$ adalah koefisien regresi dan $u$ adalah error term.

Berdasarkan hasil estimasi model tersebut, jika $\beta_{1}$ lebih besar dari hasil penjumlahan $\beta_{2}$ sampai $\beta_{5}$ maka tidak terjadi flypaper effect atau daerah tersebut sudah mandiri.Sebaliknya, $\beta_{1}$ lebih kecil dari salah satu nilai $\beta_{2}$ sampai $\beta_{5}$ maka daerah tersebut belum mandiri atau flypaper effect terjadi.

Untuk melengkapi analisis model tersebut, studi ini juga menambahkan analisis deskriptif. Analisis tambahan ini untuk membandingkan Aceh dengan provinsi lainnya di Indonesia berdasarkan struktur ekonomi dan kinerja keuangannya.Dengan analisis seperti ini, studi ini ingin menunjukkan bahwa provinsi-provinsi dengan struktur ekonomi yang tidak bergantung sangat tinggi kepada sektor trandisional dalam jangka panjang mampu mengurangi ketergantungan keuangan dengan Pemerintah. Salah satu indikatornya adalah perkembangan dan kontribusi PAD di daerah tertentu yang cenderung meningkat dan cukup besar 
sehingga dapat digunakan sebagai sumber pendapatan utama yang lebih dominan dibandingkan dengan transfer Pemerintah. Dalam analisis kualitatif deskriptif ini, beberapa variabel makroekonomi ditampilkan dan dianalisis dengan melihat trend an proporsinya terhadap pendapatan regional masing-masing provinsi antara lainpendapatan per kapita, PAD per kapita, serta Dana Perimbangan per kapita dari masing-masing provinsi tersebut.

\section{HASIL DAN PEMBAHASAN}

\section{Perkembangan Belanja Daerah di Aceh}

Aceh yang terdiri dari 23 kabupaten/kota memiliki tren belanja daerah yang terus meningkat, khususnya setelah adanya transfer dana dalam bentuk Dana Otonomi Khusus dan Tambahan Dana Bagi Hasil Minyak dan Gas Bumi. Rata-rata belanja daerah meningkat dari Rp 544,58 miliar pada tahun 2011 menjadi Rp 668,87 miliar pada tahun 2013. Sebagaimana ditunjukkan pada Gambar 2, belanja daerah Kabupaten Aceh Utara adalah yang tertinggi mencapai Rp1,2 triliun pada tahun 2011 dan kemudian meningkat menjadi Rp1,5 triliun pada tahun 2013. Kabupaten ini menjadi yang tertinggi dalam hal belanja daerah karena di sana beroperasi beberapa proyek vital, PT. Exxon Mobil, PT. Kertas Kraft Aceh, PT. PIM, dan PT Arun, sehingga memberikan kontribusi terhadap pendapatan daerah. Sedangkan Kabupaten Subulussalam memiliki belanja daerah terkecil hanya sebesar Rp316,33 miliar di tahun 2011 kemudian meningkat menjadi Rp349,44 miliar pada tahun 2013.

\section{Pendapatan Asli Daerah}

Lima sumber PAD kabupaten/kota di Aceh berasal dari Pajak Daerah, Retribusi Daerah, Hasil Pengelolaan Kekayaan Daerah yang Dipisahkan, Zakat/Infaq/Sedekah, dan Lain-lain Pendapatan yang Sah. Selama periode 2011-2013, secara umum PAD di 23 kabupaten/kota di Aceh meningkat, kecuali di Lhokseumawe, Langsa dan Subulussalam yang berfluktuasi sedikit. Kota Banda Aceh mempunyai PAD terbesar yang didominasi oleh komponen Lain-lain PAD yang Sah yaitu sebesar Rp38,83 miliar, diikuti oleh Pajak Daerah sebanyak Rp36,46 miliar. Kota Banda Aceh sebagai ibu kota Provinsi Aceh lebih mandiri dibandingkan dengan kabupaten/kota lainnya karena PAD yang dimiliki relatif lebih besar. Sedangkan Kota 
Subulussalam memiliki PAD terendah hanya Rp6,83 miliar tahun 2011 dan Rp7,88 miliar tahun 2013.

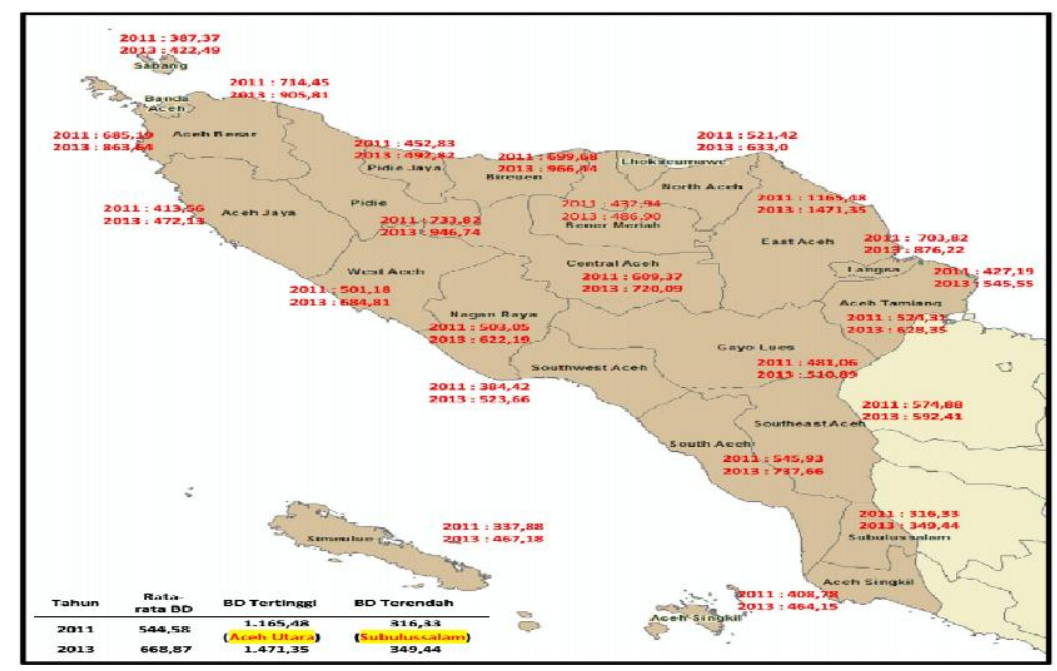

Sumber: Dinas Keuangan Aceh, 2014.

Gambar 2. Realisasi Belanja Daerah Kabupaten/Kota di Provinsi Aceh, 2011-2013 (Miliar Rp)

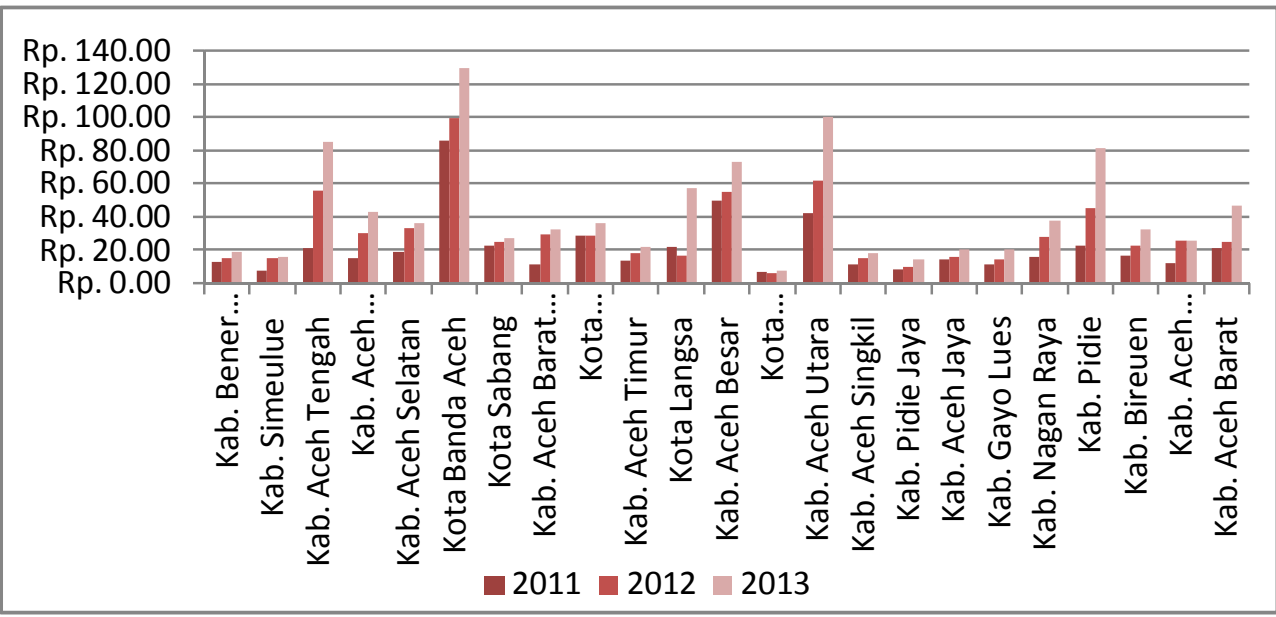

Sumber : Dinas Keuangan Aceh, 2014.

Gambar 3. Realisasi Pendapatan Asli Daerah Kabupaten/Kota di Provinsi Aceh, 2011-2013 (Miliar Rp) 


\section{Pemilihan Model Estimasi}

Ada tiga model yang dapat digunakan untuk melakukan pengujian dengan menggunakan data panel. Pertama, model Pooled Least Square (PLS) atau sering disebut dengan Common Effect Model (CEM) yang secara sederhana menggabungkan (pooled) seluruh data time series dengan data cross section yang kemudian mengestimasi model tersebut menggunakan metode Ordinary Least Square (OLS). Kedua, Fixed Effect Model (FEM) yang melakukan pertimbangan atau perhitungan terhadap kemungkinan bahwa peneliti menghadapi masalah omitted variables dimana masalah ini diduga dapat memberikan pengaruh perubahan pada intercept time series atau cross section. Ketiga, Random Effect Model (REM) yang berguna untuk memperbaiki efisiensi proses Least Square yang memperhitungkan error dari cross section dan time series.

Untuk menentukan model terbaik, beberapa uji dilakukan diantaranya uji Chow atau biasa disebut dengan uji $\mathrm{F}$ untuk menentukan apakah menggunakan model PLS (CEM) atau menggunakan FEM. Selanjutnya, uji Hausman untuk menentukan apakah memilih REM atau FEM setelah terbukti dengan uji Chow bahwa FEM yang lebih tepat. Jika dengan kedua pengujian tersebut FEM merupakan model yang paling tepat, maka tidak perlu dilakukan pengujian LM. Namun jika dalam uji Chow menunjukkan bahwa PLS (CEM) merupakan model yang paling tepat, maka perlu dilakukan pengujian LM untuk membuktikan apakah benar bahwa PLS (CEM) yang paling tepat atau REM.

Seperti disarikan pada Tabel 1, Uji Chow menunjukkan bahwa nilai probabilitas dari F-tsest sebesar 0,0014 dan Chi-square sebesar 0,0000 yang lebih kecil dari $\alpha$ sebesar 5 persen. Maka model yang paling sesuai adalah Fixed Effect Model.

Tabel 1. Hasil Uji Chow (Uji F) untuk Menentukan PLS atau FEM

\begin{tabular}{lrrr}
\hline \hline Effects Test & Statistic & d.f. & Prob. \\
\hline \hline Cross-section F & 2,939101 & $(22,41)$ & 0,0014 \\
Cross-section Chi-square & 65,319295 & 22 & 0,0000 \\
\hline \hline
\end{tabular}

Sumber : Hasil Studi dengan Eviews 7, 2014. 
Demikian juga halnya, sebagaimana disajikan Tabel 2, secara statistik Uji Hausman menunjukkan bahwa FEM adalah model yang paling tepat.

Tabel 2. Hasil Uji Hausman untuk Menentukan REMatau FEM

\begin{tabular}{lrrr}
\hline \hline Test Summary & Chi-Sq. Statistic & Chi-Sq. d.f. & Prob. \\
\hline \hline Cross-section random & 51,283305 & 5 & 0,0000 \\
\hline \hline
\end{tabular}

Sumber : Hasil Studi dengan Eviews 7, 2014.

\section{Estimasi Model yang Dipilih}

Berdasarkan pengujian pemilihan model yang akan digunakan dalam estimasi model yang dipilih, FEMmerupakan model yang sepertinya menjadi kandidat model yang digunakan dalam studi ini. Hasil estimasi FEM adalah sebagai berikut:

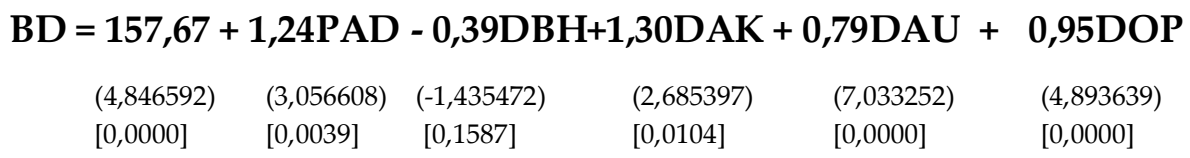

Adj. $R^{2}=0,988520 \quad D W=3,46$

Meskipun berdasarkan pengujian pemilihan model FEM adalah yang terbaik, namun hasil estimasi FEM tidak dapat digunakan karena terdapat bias pada koefisien dari cross section sehingga estimasi yang dilakukan kurang tepat. Hal ini ditunjukkan dengan koefisien Langsa sebesar 650,92 yang melebihi koefisien Banda Aceh yang hanya sebesar -29,59. Seharusnya koefisien Banda Aceh lebih besar dari Langsa karena BD Banda Aceh lebih besar dari BD Langsa. Permasalahan estimasi ini diduga karena di dalam penelitian ini cross section (26 kabupaten/kota) lebih besar daripada time series ( 3 tahun), sehingga lebih tepat menggunakan PLS. Jika cross section lebih kecil dari time series maka lebih tepat menggunakan FEM atau REM. Sedangkan jika jumlah cross section sama dengan jumlah time series, maka dapat dipilih untuk menggunakan PLS, FEM maupun REM.

Oleh karena itu, estimasi model yang paling tepat dalam studi ini adalah dengan model PLS seperti ditunjukkan di bawah ini: 


\section{$\mathrm{BD}=1,05 \mathrm{PAD}+1,08 \mathrm{DBH}+0,83 \mathrm{DAK}+1,03 \mathrm{DAU}+0,95 \mathrm{DOP}$

$\begin{array}{lrrrr}(4,927071) & (23,61253) & (2,395414) & (19,77519) & (7,006555) \\ {[0,0000]} & {[0,0000]} & {[0,0195]} & {[0,0000]} & {[0,0000]}\end{array}$

Adj. $R^{2}=0,979183 \quad D W=2,24$

PAD berpengaruh secara statistik terhadap BD dan memiliki hubungan yang positif. Hal ini bermakna setiap PAD meningkat sebesar Rp1 miliar, maka BD akan meningkat sebesar Rp1,05 miliar.DBH juga berpengaruh secara statsitik terhadap BD, dengan nilai p-value sebesar 0,0000. Hubungan kedua variabel ini adalah positif yang berarti bahwa ketika DBH meningkat sebesar Rp1 miliar, maka BD akan meningkat sebesar Rp1,08 miliar. Selain itu, variabel DAK secara signifikan berbengaruh terhadap BD dengan nilai p-value sebesar 0,0195dan arah hubungan mereka positif. Ini berarti BD akan meningkat sebesar Rp0,83 miliar ketika DAK meningkat sebesar Rp1 miliar.Nilai p-value DAU sebesar 0.0000 menunjukkan bahwa DAU berpengaruh signifikan terhadap BD. Arah hubungannya positif sehingga setiap kenaikan DAU sebesar Rp1 miliar akan diikuti dengan kenaikan BD sebesar Rp1,03 miliar. Terakhir, DOP secara signifikan mempengaruhi BD dengan nilai p-value sebesar 0,0000. BD akan meningkat sebesar Rp0,95 miliar ketika adanya peningkatan DOP sebesar Rp1 miliar.

Untuk menentukan ada tidaknya flypaper effect dapat dilihat dari perbandingan besar koefisien PAD dengan koefisien variabel lainnya.Dengan menggunakan hasil estimasi PLS, terlihat bahwa koefisien $\mathrm{DBH}$ lebih besar jika dibandingkan dengan variabel PAD. Jadi dapat disimpulkan bahwa terdapat flypaper effect di Aceh karena pengaruh dari DBH terhadap BD lebih besar jika dibandingkan dengan pengaruh variabel PAD terhadap BD.

\section{Analisis Deskriptif}

Tabel 3 menunjukkan bahwa DKI Jakarta memiliki kontribusi sektor tersier tertinggi yaitu sebesar 71,46 persen dari total PDRB, diikuti oleh Bali sebesar 66,26 persen. Sedangkan Aceh sangat jauh tertinggal dibandingkan kedua daerah tersebut, yaitu sebesar 41,50 persen. Hal ini memperkuat indikasi bahwa Aceh masih belum mandiri karena sektor tersiernya masih relatif kecil dibandingkan dengan daerah lainnya. 
Tabel 3. Peringkat Provinsi Berdasarkan Kontribusi Sektor Primer, Sekunder dan Tersier terhadap PDRB, ADHB dengan Migas, 2012.

\begin{tabular}{|c|c|c|c|c|c|}
\hline \multirow{2}{*}{ Provinsi } & \multicolumn{3}{|c|}{ Sektor (\%) } & \multirow{2}{*}{$\begin{array}{c}\text { PDRB } \\
\text { (Rp juta) }\end{array}$} & \multirow{2}{*}{ Peringkat } \\
\hline & Primer & Sekunder & Tersier & & \\
\hline DKI Jakarta & 0,56 & 27,98 & 71,46 & 1.103.738.000 & 1 \\
\hline Bali & 17,63 & 16,11 & 66,26 & 83.939 .000 & 2 \\
\hline Maluku & 29,39 & 6,97 & 63,64 & 11.469 .000 & 3 \\
\hline DI Yogyakarta & 15,32 & 25,47 & 59,21 & 57.034 .000 & 4 \\
\hline Gorontalo & 30,58 & 12,50 & 56,92 & 10.368 .000 & 5 \\
\hline Sumatera Barat & 25,91 & 18,78 & 55,31 & 110.104 .000 & 6 \\
\hline Sulawesi Utara & 20,38 & 25,53 & 54,09 & 47.198 .000 & 7 \\
\hline Nusa Tenggara Timur & 37,33 & 9,13 & 53,54 & 35.253 .000 & 8 \\
\hline Kalimantan Tengah & 35,20 & 13,57 & 51,23 & 55.876 .000 & 9 \\
\hline Sulawesi Selatan & 31,39 & 18,78 & 49,83 & 159.427 .000 & 10 \\
\hline Jawa Timur & 19,24 & 32,41 & 48,35 & 1.001 .721 .000 & 11 \\
\hline Bengkulu & 43,13 & 8,76 & 48,11 & 24.173 .000 & 12 \\
\hline Sumatera Utara & 23,20 & 29,70 & 47,10 & 351.118 .000 & 13 \\
\hline Sulawesi Tenggara & 37,79 & 16,42 & 45,79 & 36.601 .000 & 14 \\
\hline Kalimantan Barat & 26,10 & 28,28 & 45,62 & 75.027 .000 & 15 \\
\hline Maluku Utara & 39,56 & 16,42 & 44,02 & 6.918 .000 & 16 \\
\hline Jawa Barat & 13,54 & 42,62 & 43,84 & 946.861 .000 & 17 \\
\hline Sulawesi Barat & 43,75 & 13,11 & 43,14 & 14.408 .000 & 18 \\
\hline Nusa Tenggara Barat & 44,33 & 12,68 & 42,99 & 49.529 .000 & 19 \\
\hline Lampung & 37,88 & 19,46 & 42,66 & 144.561 .000 & 20 \\
\hline Sulawesi Tengah & 43,48 & 14,83 & 41,69 & 51.062 .000 & 21 \\
\hline Aceh & 38,16 & 20,34 & 41,50 & 96.161 .000 & 22 \\
\hline Kalimantan Selatan & 42,93 & 15,62 & 41,45 & 75.923 .000 & 23 \\
\hline Jawa Tengah & 19,60 & 39,80 & 40,60 & 556.480 .000 & 24 \\
\hline Banten & 7,96 & 53,40 & 38,64 & 212.857 .000 & 25 \\
\hline Kep. Bangka Belitung & 34,42 & 28,30 & 37,28 & 34.325 .000 & 26 \\
\hline Sumatera Selatan & 37,90 & 28,66 & 33,44 & 206.331 .000 & 27 \\
\hline Kep. Riau & 11,80 & 56,37 & 31,83 & 91.717 .000 & 28 \\
\hline Papua & 59,10 & 15,09 & 25,81 & 77.765 .000 & 29 \\
\hline Jambi & 53,76 & 26,47 & 19,77 & 72.654 .000 & 30 \\
\hline Papua Barat & 18,65 & 61,62 & 19,73 & 72.654 .000 & 31 \\
\hline Kalimantan Timur & 56,00 & 26,26 & 17,74 & 419.102 .000 & 32 \\
\hline
\end{tabular}

Sumber : Badan Pusat Statistik, 2014.

Selanjutnya analisis deskriptif membandingkan Aceh dengan provinsi lainnya yang memiliki karakteristik yang relatif sama yaitu kontribusi 
sektor primer yang relatif besar.Aceh dengan kontribusi sektor Primer yang lebih kecil tetapi memiliki tingkat ketergantungan yang paling tinggi.Berbeda dari Kalimantan Timur, meskipun hampir setengah kontribusi PDRB berasal dari sektor primer tetapi memiliki PAD cukup tinggi hampir setengah dari total penerimaan daerah.

Tabel 4. Struktur Penerimaan Daerah Berdasarkan Besarnya Sektor Primer terhadap PDRB, 2012

\begin{tabular}{llccccc}
\hline No & \multicolumn{1}{c}{ Provinsi } & $\begin{array}{c}\text { Kontribusi } \\
\text { Sektor } \\
\text { Primer (\%) }\end{array}$ & $\begin{array}{c}\text { \% PAD } \\
\text { terhadap } \\
\text { Pendapatan }\end{array}$ & $\begin{array}{c}\text { \% DP } \\
\text { terhadap } \\
\text { Pendapatan }\end{array}$ & $\begin{array}{c}\text { Total } \\
\text { Pendapatan } \\
\text { Daerah } \\
\text { (miliar) }\end{array}$ \\
\hline 1 & Bengkulu & 43,13 & $31 \%$ & $57 \%$ & $\mathrm{Rp}$ & $1.562,53$ \\
2 & Sulawesi Tengah & 43,48 & $37 \%$ & $61 \%$ & $\mathrm{Rp}$ & $1.410,59$ \\
3 & Kalimantan Selatan & 42,93 & $57 \%$ & $35 \%$ & $\mathrm{Rp}$ & $4.381,68$ \\
4 & Papua & 59,10 & $22 \%$ & $78 \%$ & $\mathrm{Rp}$ & $2.710,38$ \\
5 & Kalimantan Timur & 56,00 & $45 \%$ & $52 \%$ & $\mathrm{Rp}$ & $11.816,60$ \\
6 & Aceh & 38,16 & $10 \%$ & $90 \%$ & $\mathrm{Rp}$ & $9.180,14$ \\
\hline
\end{tabular}

Sumber : Badan Pusat Statistik, 2014 (diolah)

Perbandingan selanjutnya dilakukan antara Aceh dan provinsi lainyang dianggap lebih mandiri seperti DKI Jakarta dan Bali. Kedua provinsi ini memilikistruktur ekonomi yang lebih baik dibandingkan dengan Aceh.Perbandingan ini dilakukan dengan melihat struktur penerimaan daerah serta struktur perekonomian.

DKI Jakarta memiliki porsi PAD terhadap penerimaan daerah terbesar yaitu mencapai 62 persen, kemudian Bali 56 persen dan Aceh hanya 10 persen.Sebaliknya, Aceh memiliki porsi DP terbesar dalam struktur penerimaan daerah mencapai 90 persen kemudian disusul DKI Jakarta 33 persen dan terakhir Bali sebesar 25 persen. Ini menunjukkan bahwa Aceh sangat tergantung terhadap DP karena 90 persen pendapatan Aceh bersumber dari DP, dan sisanya hanya sebanyak 10 persen dari PAD. 
Tabel 5. Struktur Penerimaan dan Ekonomi Daerah, 2012 (miliar dan persen)

\begin{tabular}{llccc}
\hline No. & Dasar Pembanding & Jakarta & \multicolumn{1}{l}{ Bali } & \multicolumn{1}{l}{ Aceh } \\
\hline 1 & Struktur Penerimaan Daerah & & & \\
1.1 & Total Pendapatan Daerah & Rp. 35.379 & Rp. 3.633 & Rp. 9.180 \\
1.2 & PAD & Rp. 22.041 & Rp. 2.042 & Rp. 902 \\
1.3 & Dana Perimbangan (miliar) & Rp. 11.555 & Rp. 908 & Rp. 8.278 \\
& \% PAD terhadap pendapatan & $62 \%$ & $56 \%$ & $10 \%$ \\
& \% DP terhadap pendapatan & $33 \%$ & $25 \%$ & $90 \%$ \\
2.1 & Struktur Ekonomi Daerah & & & \\
& PDRB ADHK 2000 & Rontribusi sektor primer*) 449.821 & Rp. 32.804 & Rp. 36.600 \\
& Kontribusi sektor sekunder**) & $0,3 \%$ & $19,2 \%$ & $34,0 \%$ \\
& Kontribusi sektor tersier**) & $25,2 \%$ & $15,8 \%$ & $17,5 \%$ \\
\hline
\end{tabular}

Sumber : Badan Pusat Statistik, 2014.

Catatan : ${ }^{*}$ ) terdiri dari sektor pertanian; dan sektor pertambangan dan **) penggalian terdiri dari sektor industri pengolahan; sektor listrik, gas dan ***) air minum; dan sektor bangunan dan kontruksi. terdiri dari sektor perdagangan, hotel dan restoran; sektor pengangkutan dan komunikasi; sektor keuangan, persewaan dan jasa perusahaan; dan sektor jasa-jasa.

Dari struktur ekonomi daerah,kontribusi terbesar terhadap PDRB di DKI Jakarta adalah sektor tersier mencapain sebesar 74,5 persen, diikuti oleh sektor sekunder 25,2 persen dan sektor primer hanya 0,3 persen. Kontribusi sektor terbesar di Bali adalah sektor tersier sebesar 64,9 persen, sedangkan sektor sekunder dan primer masing-masing sebesar 15,8 persen dan 19,2 persen. Di Aceh, sektor tersier merupakan sektor yang terbesar yaitu 48,5 persen, diikuti sektor primer 34,0 persen dan sekunder 17,5 persen. Aceh masih belum memiliki potensi besar dalam meningkatkan PDRB dari sektor tersier. Hal ini juga menunjukkan Aceh masih tergantung terhadap sektor primer yang didominasi di bidang pertanian. 


\section{SIMPULAN DAN SARAN}

Pendapatan Asli Daerah, Dana Bagi Hasil, Dana Alokasi Khusus, Dana Alokasi Umum, dan Dana Otonomi Khusus dan Penyesuaian, masingmasing secara statistik memiliki pengaruh yang positif terhadap Belanja Daerah. Karena koefisien PAD lebih kecil dibandingkan dengan koefisien $\mathrm{DBH}$, flypaper effect terjadidi Aceh sehingga kemandirian daerah dalam otonomi daerah belum berjalan di Aceh. Provinsi DKI Jakarta dan Bali relatif lebih mandiri dibandingkan dengan Provinsi Aceh karena struktur perekonomian kedua daerah tersebut relatif didominasi oleh sektor tersier sehingga memiliki kontribusi PAD yang melebihi kontribusi dana perimbangan terhadap pendapatan

Berdasarkan hasil analisa ini, dalam mengatasi flypaper effect pemerintaha Aceh harus meningkatan PAD dengan cara mendorong serta merubah sektor perekonomian dari ekonomi tradisional menjadi ekonomi kreatif yang didominasi oleh sektor tersier. Ketika daerah didominasi oleh sektor tersier, maka secara umum daerah tersebut akan memiliki kontribusi PAD terhadap belanja daerah yang relatif lebih besar. Selain itu, belanja daerah seharusnya dialokasikan pada belanja modal yang bersifat jangka panjang dan memiliki multiplier effect yang besar terhadap pertumbuhan ekonomi.

\section{DAFTAR PUSTAKA}

Badan Pusat Statistik. 2014. PDRB Menurut Lapangan Usaha ADHK 2000 di Provinsi Jakarta, Bali, dan Aceh 2012.Diakses padahttp://www.bps.go.id.tanggal 5 Oktober 2014. . 2014. Pendapatan, PAD, dan Dana Perimbangan Provinsi Jakarta, Bali, dan Aceh 2010-2012.Diakses pada http://www.bps.go.id. tanggal 5 Oktober 2014.

Burhanuddin, Ahmad. Pengaruh Belanja Pegawai, Investasi Pemerintah dan Pembayaran Utang Pemerintah Daerah terhadap Fenomena Flypaper Effect. Accounting Analysis JournalVol. 1 No.1. 2010.

Dinas Keuangan Aceh. 2014. APBD 23 Kabupaten/Kota Provinsi Aceh 2011-2013.

Gramlich, Edward. State and Local Governments and their Budget Constraint.International Economic ReviewVol . 10. June 1969, (163182).

QE Journal | Vol.03 - No.04 December 2014 - 212 
Gujarati, Damodar N. "Basic Econometrics, 4th ed". McGraw-Hill. New York, 2004.

Henderson, James. Local Government Expendi tures: A Social Welfare Analysis. Review of Economics and Statistics, Vol. 50, May 1968, (156163).

Kementerian Keuangan Republik Indonesia. 2014. Anggaran Belanja untuk Daerah Tahun 2004-2013. Diakses pada http://www.kemenkeu.go.id. tanggal 07 Maret 2014. . (2014). Leaflet-djpk.Diakses pada www.djpk.kemenkeu.go.id/publikasi /leaflet-djpk tanggal 25 Mei 2014.

Listiorini. (2012). “Fenomena Flypaper Effect pada Dana Perimbangan dan Pendapatan Asli Daerah terhadap Belanja Daerah pada Kabupaten/Kota di Sumatera Utara". Jurnal Keuangan dan Bisnis. Vol. 4 No. 2, Juli 2012.

Maimunah, Mutiara. (2006). “Flypaper Effect pada Dana Alokasi Umum (DAU) dan Pendapatan Asli Daerah (PAD) terhadap Belanja Daerah pada Kabupaten/Kota di Pulau Sumatera". Simposium Nasional Akuntansi IX. Padang.

PMK Nomor 06/PMK.07/2012 tentang Pelaksanaan dan Pertanggungjawaban Anggaran Transfer ke Daerah.

PP Nomor 55 Tahun 2005 tentang Dana Perimbangan.

PP Nomor 58 Tahun 2005 tentang Pengelolaan Keuangan Daerah .

Turnbull, G.K. Fiscal Illusion, Uncertainty, and the Flypaper Effect.Journal of Public Economics,Vol.48(2), Juli 1992, (207-223).

Undang-Undang Nomor 11 Tahun 2006 tentang Pemerintahan Aceh.

Undang-Undang Nomor 36 Tahun 2008 tentang Perubahan Pajak Penghasilan.

Undang-Undang Nomor 17 Tahun 2003 tentang Keuangan Negara.

Undang-Undang Nomor 18 Tahun 1997 tentang Pajak Daerah dan Retribusi Daerah. 
Undang-Undang Nomor 21 Tahun 2001 tentang Otonomi Khusus bagi Provinsi Papua.

Undang-Undang Nomor 22 Tahun 1999 tentang Pemerintahan Daerah.

Undang-Undang Nomor 25 Tahun 1999 tentang Perimbangan Keuangan Antara Pemerintah Pusat dan Daerah.

Undang-Undang Nomor 27 Tahun 2003 tentang Panas Bumi.

Undang-Undang Nomor 28 Tahun 2009 tentang Pajak Daerah dan Retribusi Daerah.

Undang-Undang Nomor 33 Tahun 2004 tentang Perimbangan Keuangan antara Pemerintah Pusat dan Pemerintah Daerah.

Undang-Undang Nomor 7 Tahun 1983 tentang Pajak Penghasilan. 


\section{Lampiran 1: Estimasi dengan Fixed Effect Model}

Dependent Variable: BD?

Method: Pooled Least Squares

Date: 10/22/14 Time: 21:22

Sample: 20112013

Included observations: 3

Cross-sections included: 23

Total pool (balanced) observations: 69

\begin{tabular}{crrrr}
\hline \hline Variable & Coefficient & Std. Error & t-Statistic & Prob. \\
\hline \hline C & 157,6615 & 32,53038 & 4,846592 & 0,0000 \\
PAD? & 1,238519 & 0,405194 & 3,056608 & 0,0039 \\
DBH? & $-0,390683$ & 0,272164 & $-1,435472$ & 0,1587 \\
DAK? & 1,295928 & 0,482584 & 2,685397 & 0,0104 \\
DAU? & 0,788609 & 0,112126 & 7,033252 & 0,0000 \\
DOP? & 0,952496 & 0,194640 & 4,893639 & 0,0000
\end{tabular}

Fixed Effects (Cross)

$\begin{array}{cr}\text { _ABARAT--C } & -57,49106 \\ \text { _ABESAR--C } & -100,5378 \\ \text { _ASELATAN--C } & -33,04481 \\ \text { _ASINGKIL--C } & 14,28072 \\ \text { _ATENGAH--C } & -31,26868 \\ \text { _ATENGGARA--C } & -19,34950 \\ \text { _ATIMUR--C } & -49,72893 \\ \text { _AUTARA--C } & -53,77881 \\ \text { _BIREUEN--C } & 29,64277 \\ \text { _PIDIE--C } & 67,18073 \\ \text { _SIMEULUE--C } & -61,91735 \\ \text { BANDAACEH--C } & -29,59438 \\ \text { _SABANG--C } & -69,98354 \\ \text { _LANGSA--C } & 650,9217 \\ \text { _HOKSEUMAWE--C } & -57,89674 \\ \text { _GAYOLUES--C } & -41,95465 \\ \text { ABARATDAYA--C } & -53,12601 \\ \text { _AJAYA--C } & -26,73870 \\ \text { _NAGANRAYA--C } & -18,75885 \\ \text { _ATAMIANG--C } & -7,453485 \\ \text { BENERMERIAH--C } & 25,68567 \\ \text { SUBULUSSALAM--C } & -30,73795 \\ \text { _PIDIEJAYA--C } & -44,35037\end{array}$

Effects Specification

Cross-section fixed (dummy variables)

\begin{tabular}{llll}
\hline \hline R-squared & 0,993078 & Mean dependent var & 597,4645 \\
Adjusted R-squared & 0,988520 & S.D. dependent var & 217,3570 \\
S.E. of regression & 23,28862 & Akaike info criterion & 9,424867
\end{tabular}

QE Journal |Vol.03 - No.04 December 2014 - 215 
Lampiran 2: Estimasi dengan Pool Least Square (PLS) atau Common Effect Model (CEM)

Dependent Variable: BD?

Method: Pooled Least Squares

Date: 10/22/14 Time: 21:20

Sample: 20112013

Included observations: 3

Cross-sections included: 23

Total pool (balanced) observations: 69

\begin{tabular}{crrrr}
\hline \hline Variable & Coefficient & Std. Error & t-Statistic & Prob. \\
\hline \hline PAD? & 1,054784 & 0,214079 & 4,927071 & 0,0000 \\
DBH? & 1,080192 & 0,045747 & 23,61253 & 0,0000 \\
DAK? & 0,826761 & 0,345143 & 2,395414 & 0,0195 \\
DAU? & 1,031442 & 0,052158 & 19,77519 & 0,0000 \\
DOP? & 0,948598 & 0,135387 & 7,006555 & 0,0000 \\
\hline \hline R-squared & 0,980408 & Mean dependent var & & 597,4645 \\
Adjusted R-squared & 0,979183 & S.D. dependent var & & 217,3570 \\
S.E. of regression & 31,36025 & Akaike info criterion & & 9,798663 \\
Sum squared resid & 62941,77 & Schwarz criterion & & 9,960555 \\
Log likelihood & $-333,0539$ & Hannan-Quinn criter, & & 9,862891 \\
Durbin-Watson stat & 2,243185 & & & \\
\hline \hline
\end{tabular}

